\title{
Factors Associated with Pain Intensity in Patients Undergoing Orthodontic Treatment Based on Mini-Implants
}

\author{
Eugen Bud, Alexandru Vlasa, Manuela Chibelean, Krisztina Martha, Mariana Păcurar, \\ Anamaria Bud, Daniela Esian
}

Department of Dental Medicine, "George Emil Palade” University of Medicine, Pharmacy, Science and Technology, Târgu Mureș, Romania

${ }^{*}$ All authors contributed equally to this research.

\section{CORRESPONDENCE}

Alexandru Vlasa

Str. Gheorghe Marinescu nr. 38

540139 Târgu Mureș, Romania

Tel: +40 742825920

E-mail: alexandru.vlasa@gmail.com

\section{ARTICLE HISTORY}

Received: February 28, 2021

Accepted: March 29, 2021
Eugen Silviu Bud • Str. Gheorghe Marinescu nr. 38, 540139 Târgu Mureș, Romania. Tel: +40 744437661 E-mail eugen.bud@umfst.ro

Manuela Chibelean · Str. Gheorghe Marinescu nr. 38 540139 Târgu Mureș, Romania. Tel: +40 265215551 E-mail: manuela.chibelean@umfst.ro

Krisztina Martha • Str. Gheorghe Marinescu nr. 38 540139 Târgu Mures, Romania. Tel: +40 265215 551, E-mail: krisztina.martha@umfst.ro

Mariana Păcurar • Str. Gheorghe Marinescu nr. 38 540139 Târgu Mureș, Romania. Tel: +40 265215 551, E-mail: mariana.pacurar@umfst.ro

Anamaria Bud - Str. Gheorghe Marinescu nr. 38 540139 Târgu Mureș, Romania. Tel: +40 265215 551, E-mail: anamaria.bud@umfst.ro

Daniela Esian • Str. Gheorghe Marinescu nr. 38 540139 Târgu Mures, Romania. Tel: +40 265215 551, E-mail: daniela.esian@umfst.ro

\begin{abstract}
Introduction: Pain is currently reported as the most common side effect associated with orthodontic treatment. The aim of this study was to evaluate the factors associated with the intensity of pain perception during orthodontic procedures consisting in anesthesia, orthodontic miniimplant placement and removal, as well as during the postoperative period following these procedures. Material and Methods: The study included 50 young adults with a permanent dentition in need of orthodontic treatment. The pain assessment was based on visual analogue scale (VAS), using self-report questions from approved questionnaires. Pain severity was analyzed in relation to: anesthesia, implant placement, implant removal, implant movement, elastic traction and gingiva/bone pain around the implant. The study lot was divided into Group 1 - patients experiencing a pain degree of 1 or 2 , and Group 2 - patients experiencing a pain degree of 3 or 4 during implant placement. Results: The maximum pain intensity (PI) was recorded during implant placement, which has been associated with a Pl of $2.4 \pm 0.8$ (95\% Cl: 2.17-2.63), followed by implant removal $(\mathrm{PI}=2.36 \pm 0.66,95 \% \mathrm{Cl}$ : $2.17-2.54)$, gingiva/bone pain around the implant $(\mathrm{PI}$ $=2.32 \pm 2.58,95 \% \mathrm{Cl}: 2.15-2.48$ ), and elastic traction ( $\mathrm{Pl}=2.26 \pm 0.63,95 \% \mathrm{Cl}: 2.08-2.44)$. Male gender was present in a significantly higher extent in the group of patients presenting a high intensity pain during implant placement (86.3\% in Group 2 vs. 3.5\% in Group 1, p <0.0001). The age group most sensitive to pain was 18 to 21 years. Conclusions: In our study, pain perception was significantly higher in males and in the 18-21 years age group. The most painful procedure during surgery was the initial moment of implant placement, followed by the moment of implant removal, gingival/bone pain around the implant, and the elastic tractions placed on the implant during anchorage.
\end{abstract}

Keywords: pain, orthodontic treatment, mini-implant, anchorage 


\section{INTRODUCTION}

The ongoing coronavirus disease (COVID-19) outbreak has impacted the mental health of patients, health workers, and the public. Efforts to contain COVID-19 and minimize the risk of cross-transmission have been implemented by multiple countries. ${ }^{1}$ This includes quarantine measures, dusk-to-dawn curfew, and 24-hour lockdown, with particular emphasis on social distancing. ${ }^{2}$ Among these measures, country-level closure of dental services except for emergency treatments has been implemented. ${ }^{3}$ Orthodontic emergencies occasionally occur, and they represent urgencies rather than emergencies. Pain and discomfort are the main reported emergencies experienced during orthodontic treatment. ${ }^{4,5}$ Several recent studies have shown that more than $95 \%$ of patients undergoing an orthodontic treatment report different levels of pain during the orthodontic procedures. ${ }^{6-8}$ The most common orthodontic procedures include bracket and archwire placement, trans-palatal bar, or more recently, mini-implant placement. The forces generated during these procedures result in the creation of various tension and compression zones in the periodontal ligament, which can lead to a painful experience for patients, who will associate pain with the implant procedure. ${ }^{6}$ At the same time, in most cases, patients undergoing orthodontic treatment are exposed to various degrees of pain on a longer term as well. In these cases, the duration of pain is not limited to the implantation procedure, but to the entire period during which the patient is carrying the mini-implant, as the pain can also result from the elastic traction of surrounding tissues or implant movement. Therefore, pain can negatively impact the quality of life of patients undergoing an orthodontic treatment, determining them to discontinue treatment.

A significant individual variation in pain perception has been described in relation to the application of orthodontic forces. ${ }^{9}$ Pain intensity is influenced by various factors such as emotional and cognitive status, and also environmental or cultural factors. Experiences of pain are always multidimensional, being highly associated with sensorial as well as affective aspects. ${ }^{6,7}$

Although pain progression after initial archwire placement has been well documented, there are no studies published so far regarding pain intensity during the placement and anchorage of orthodontic mini-implants or during the postoperative period. ${ }^{10-13}$ At the same time, there is no consensus on the role of different factors that influence the severity of pain perception in patients undergoing orthodontic treatment.

The aim of this study was to evaluate the factors that can avoid prolonging treatment time, the mental distress of orthodontic patients, and their anxiety on treatment duration and outcome. We also aimed investigate the factors associated with the intensity of pain perception during orthodontic procedures consisting in anesthesia and orthodontic mini-implant placement and removal, during the early stages of the SARS-CoV-2 pandemic.

\section{MATERIALS AND METHOD}

\section{Subjects and study design}

The study included 50 young adults with a permanent dentition in need of orthodontic treatment in whom, in order
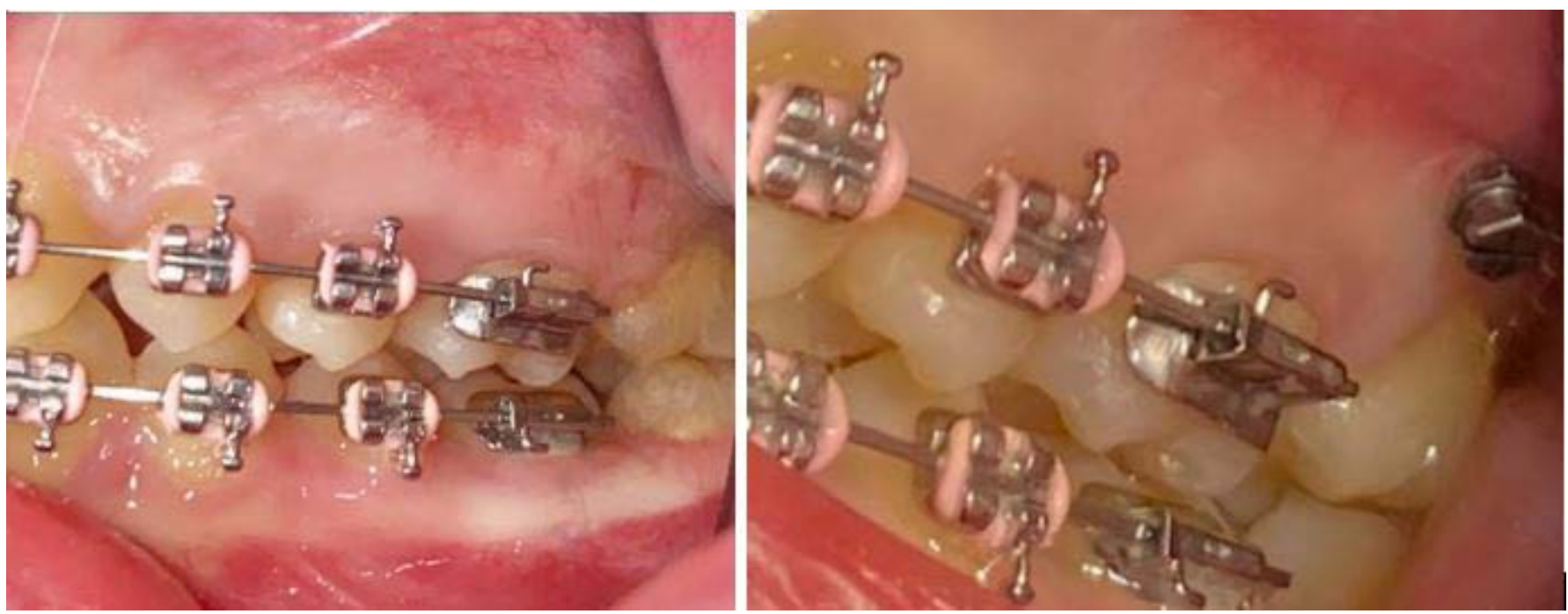

FIGURE 1. Clinical situation before (left) vs. after (right) mini-implant placement 
to shorten the treatment time and specialist visits because of the ongoing coronavirus pandemic, the therapeutic plan included mini-implant placement, followed by fixed appliances in both jaws, activated by elastic tractions (Figure 1). The study sample involved both patients with large over-jets and patients with crowding, and the need for additional anchorage of the implants varied from moderate to maximum (Figure 2).

Pain intensity was assessed using self-report questionnaires, which have been previously proved reliable and valid, as shown in Appendix $1 .{ }^{10}$ Post-operative assessment was based on the visual analogue scale (VAS), ${ }^{6}$ which is commonly used for pain quantification. Pain was defined as being of low intensity if the severity of pain was 1 or 2 on the VAS, or high intensity if the severity of pain was 3 or 4 .

The patients were asked to fill in the questionnaires at different moments: (1) immediately after implant placement (to assess the pain associated with anesthesia, implant placement, and elastic traction anchorage); (2) at the 2-month follow-up (to assess the pain associated with implant movement and gingiva/bone pain around the implant); and (3) immediately after implant removal (to assess the pain associated with implant removal).

Group 1 consisted of 28 patients $(56.0 \%)$ with low-intensity pain during implant placement, while Group 2 included 22 patients $(44.0 \%$ ) with high-intensity pain during implant placement.

The study was approved by the Ethics Committee of Algocalm Private Medical Center, Târgu Mureș, Romania (894/05.04.2020). All the included patients gave informed consent for participating in the study, and all the study procedures were in accordance with the principles stated in the Declaration of Helsinki.

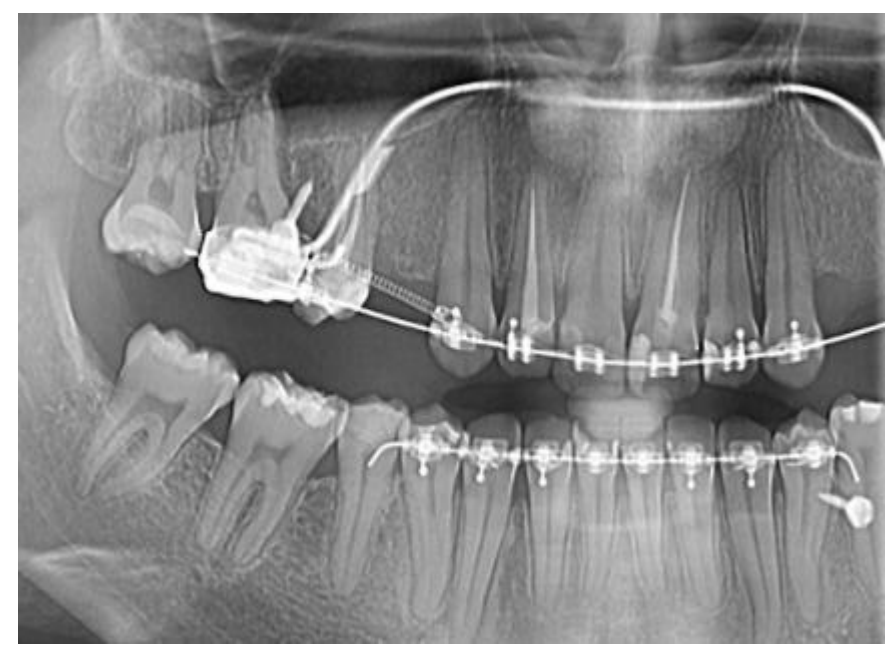

FIGURE 2. Radiographic aspect of two orthodontic mini-implants

\section{Orthodontic protocol}

All subjects were treated under the following orthodontic protocol.

Anesthesia consisted in topical use of Lidocaine ${ }^{\mathrm{Tx}}$ spray (2\% Septodont spray, Creteil, France) applied for $1 \mathrm{~min}-$ ute, followed by infiltration of $1 \mathrm{~mL}$ of articaine hydrochloride + epinephrine 1:100,000 solution (ARTICAINE ${ }^{\mathrm{m}}$ Septodont, Creteil, France), applied with the aid of a 0.30 $\times 38 \mathrm{~mm}$ gingival needle (Heraeus ${ }^{\mathrm{Tw}}$, Hanau, Germany) in the mucosal area only.

The mini-implant procedure consisted in the placement of a self-drilling mini-implant (Figure 3) measuring $11 \mathrm{~mm}$ in length and $1.8 \mathrm{~mm}$ in diameter (BioMaterials $\mathrm{s}^{\mathrm{Tix}}$, Seoul, South Korea). The mini-implants were placed with the help of a surgical kit with hand key (Anchor Plus ${ }^{\mathrm{mit}}$ Anchor Plus Screw, Los Angeles, USA). The implant placement was performed without the need for previous osteotomy, at 4 minutes after the anesthetic solution was administered.

Most $(70 \%)$ of the mini-implants were placed in the maxilla and were loaded with elastic bands after surgery. Anti-inflammatory agents (oral ibuprofen, $400 \mathrm{mg} 3 \times 1$ / day for 5 days) and painkillers (oral metamizole, $500 \mathrm{mg}$ $3 \times 1$ /day for 2 days) were recommended after surgery in all cases.

\section{Outcome measures}

We studied the association of the following factors with the intensity of pain perception in patients undergoing orthodontic treatment: age, gender, and procedure type. The following procedures were included in this analysis,

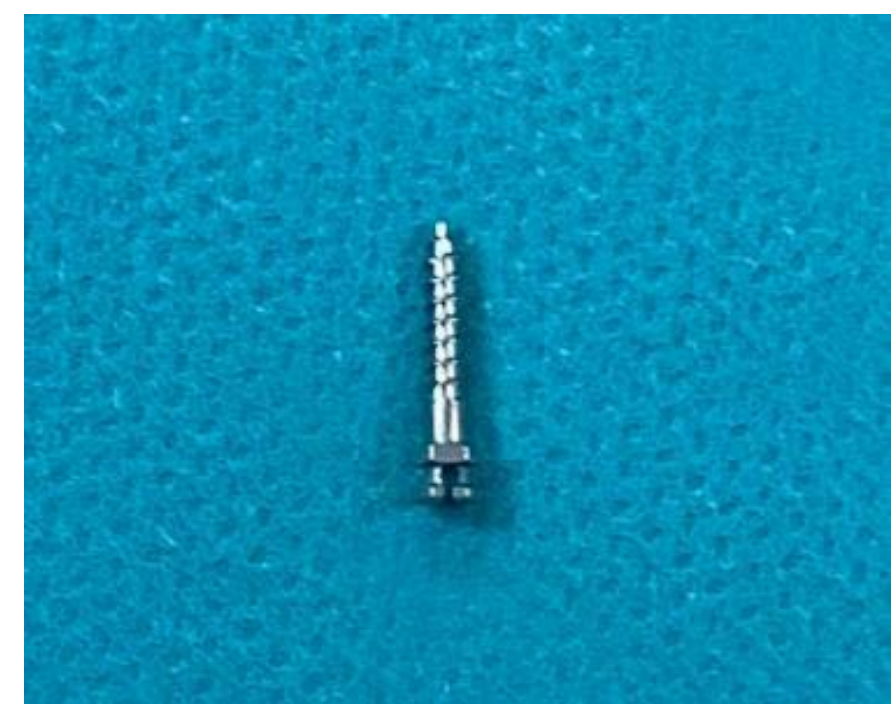

FIGURE 3. Orthodontic mini-implant used in the study 
TABLE 1. General characteristics of the study population

\begin{tabular}{lcc}
\hline Patient characteristics & & \\
\hline & $\mathbf{n}$ & $\%$ \\
Male gender & 26 & 52 \\
\hline & Mean \pm SD & $\mathbf{9 5 \%} \mathbf{C l}$ \\
Age, years & $20.84 \pm 3.29$ & $19.9-21.77$ \\
Pain intensity during anesthesia, VAS scale & $1.58 \pm 0.49$ & $1.43-1.72$ \\
Pain intensity during implant placement, VAS scale & $2.4 \pm 0.8$ & $2.17-2.63$ \\
Pain intensity during implant removal, VAS scale & $2.36 \pm 0.66$ & $2.17-2.54$ \\
Pain intensity during implant movement & $1.48 \pm 0.88$ & $1.22-1.73$ \\
Pain intensity during elastic traction & $2.26 \pm 0.63$ & $2.08-2.44$ \\
Gingival/bone pain around the implant & $2.32 \pm 2.58$ & $2.15-2.48$ \\
\hline
\end{tabular}

and pain severity was analyzed in relation to each of these procedures: anesthesia, implant placement, and implant removal. Also, pain during implant movement (if present) and elastic traction anchorage, as well as gingiva/bone pain around the implant were assessed.

We also performed a sub-analysis of pain intensity associated with different procedures in various age groups ( $<18$ years, $18-21$ years, and $>21$ years), and a sub-analysis of pain intensity in patients with and without implant movement during follow-up.

\section{Statistical analysis}

Statistical analysis was performed using the InStat ${ }^{\text {tux }}$ Graph Pad software. We used Fisher's exact test (or Student's t-test for age) to compare the characteristics of patients. Continuous values were expressed as mean and standard deviation, and statistical difference was determined using the Mann-Whitney test. Statistical significance was considered for $\mathrm{p}$ values $<0.05$, and all $\mathrm{p}$ values were two-sided.

\section{RESULTS}

Fifty patients (26 males and 24 females) were enrolled in the study, and all of them responded to the addressed questionnaire. The mean age of the study population was $20.84 \pm 3.29$ years (Table 1 ).

According to the answers provided in the questionnaires, the maximum intensity of pain was related to the procedure of implant placement, which was associated with a pain intensity (PI) of $2.4 \pm 0.8$ (95\% CI: 2.17-2.63), followed by implant removal ( $\mathrm{PI}=2.36 \pm 0.66,95 \% \mathrm{CI}: 2.17-2.54)$, gingiva/bone pain around the implant $(\mathrm{PI}=2.32 \pm 2.58,95 \%$ CI: 2.15-2.48), and elastic traction anchorage (PI $=2.26$ $\pm 0.63,95 \%$ CI: 2.08-2.44). As expected, anesthesia (PI = $1.58 \pm 0.49,95 \%$ CI: 1.43-1.72) and implant removal (PI

TABLE 2. Group characteristics according to pain intensity

\begin{tabular}{|c|c|c|c|c|c|}
\hline \multirow[b]{2}{*}{ Demographic characteristics } & \multicolumn{2}{|c|}{$\begin{array}{c}\text { Group } 1 \\
\text { Low-intensity pain (grade } \\
\begin{array}{c}\text { 1 or } 2 \text { ) during implant } \\
\text { placement } \\
n=28(56.0 \%)\end{array}\end{array}$} & \multicolumn{2}{|c|}{$\begin{array}{c}\text { Group } 2 \\
\text { High-intensity pain (grade } \\
3 \text { or } 4 \text { ) during implant } \\
\text { placement } \\
n=22(44.0 \%)\end{array}$} & \multirow[t]{2}{*}{ p value } \\
\hline & & & & & \\
\hline Age, years, mean $\pm S D$ & \multirow{2}{*}{\multicolumn{2}{|c|}{$\begin{array}{c}21.07 \pm 3.36 \\
4(3.5 \%)\end{array}$}} & \multicolumn{2}{|c|}{$20.54 \pm 3.24$} & 0.5 \\
\hline Male gender, n (\%) & & & \multicolumn{2}{|c|}{22 (86.3\%) } & $<0.001$ \\
\hline Pain intensity during the associated procedures & Mean \pm SD & $95 \% \mathrm{Cl}$ & Mean \pm SD & $95 \% \mathrm{Cl}$ & \\
\hline Pain intensity during anesthesia & $1.25 \pm 0.4$ & $1.07-1.42$ & $2.04 \pm 0.2$ & $1.95-2.14$ & $<0.0001$ \\
\hline Pain intensity during implant removal & $1.92 \pm 0.46$ & $1.74-2.72$ & $2.9 \pm 0.42$ & $2.72-3.09$ & $<0.0001$ \\
\hline Pain intensity during implant movement & $1.17 \pm 0.54$ & $0.96-1.39$ & $1.86 \pm 1.08$ & $1.38-2.34$ & 0.005 \\
\hline Pain intensity during elastic traction & $1.92 \pm 0.53$ & $1.71-2.13$ & $2.68-0.47$ & $2.47-2.89$ & $<0.0001$ \\
\hline Gingival/bone pain around the implant & $2.14 \pm 0.52$ & $1.93-2.34$ & $2.54 \pm 0.59$ & $2.28-2.81$ & 0.01 \\
\hline
\end{tabular}


TABLE 3. Pain intensity during implant-related procedures, by gender

\begin{tabular}{|c|c|c|c|c|c|}
\hline & \multicolumn{2}{|c|}{$\begin{array}{c}\text { Males } \\
n=26(52 \%)\end{array}$} & \multicolumn{2}{|c|}{$\begin{array}{c}\text { Females } \\
n=24(48 \%)\end{array}$} & \multirow[t]{2}{*}{$p$ value } \\
\hline & Mean \pm SD & $95 \% \mathrm{Cl}$ & Mean \pm SD & $95 \% \mathrm{Cl}$ & \\
\hline Pain intensity during anesthesia & $2.05 \pm 0.22$ & $1.94-2.15$ & $1.3 \pm 0.46$ & $1.12-1.47$ & $<0.0001$ \\
\hline Pain intensity during implant placement & $3.15 \pm 0.48$ & $2.92-3.37$ & $1.9 \pm 0.54$ & $1.69-2.10$ & $<0.0001$ \\
\hline Pain intensity during implant removal & $2.85 \pm 0.48$ & $2.62-3.07$ & $2.03 \pm 0.55$ & $1.86-2.24$ & $<0.0001$ \\
\hline Pain intensity during elastic traction & $2.7 \pm 0.47$ & $2.48-2.92$ & $1.96 \pm 0.55$ & $1.75-2.17$ & $<0.0001$ \\
\hline Pain intensity during implant movement & $1.85 \pm 1.08$ & $1.34-2.36$ & $1.23 \pm 0.6$ & $0.99-1.46$ & 0.01 \\
\hline Gingival/bone pain around the implant & $2.55 \pm 0.6$ & $2.26-2.8$ & $2.16 \pm 0.5$ & $1.9-2.3$ & 0.02 \\
\hline
\end{tabular}

$=1.48 \pm 0.88,95 \% \mathrm{CI}: 1.22-2.54)$ were associated with a lower degree of pain (Table 1).

There were no significant differences between the two study groups in respect to age (mean age $21.07 \pm 3.36$ years vs. $20.54 \pm 3.24$ years, $p=0.5$ ). However, male gender was present in a significantly higher extent in the group with high-intensity pain during implant placement $(86.3 \%$ in Group 2 vs. $3.5 \%$ in Group 1, p <0.0001).

There was a significantly higher level of pain perceived by patients in Group 2 for all related procedures or pain types (anesthesia: $\mathrm{p}<0.0001$; implant removal: $\mathrm{p}<0.0001$; implant movement: $\mathrm{p}=0.005$; elastic traction: $\mathrm{p}<0.0001$; gingiva/bone pain around the implant: $\mathrm{p}=0.01$ ) (Table 2 ), indicating that patients in this group showed a higher susceptibility to pain, manifested during all implant-related procedures and also during the follow-up.

Sub-analysis of the pain intensity according to gender showed clearly that males exhibited a higher sensibility to pain than females during all implant-related procedures (2.05 vs. $1.3, \mathrm{p}<0.0001$ for anesthesia, 3.15 vs. 1.9 , $\mathrm{p}<0.0001$ for implant placement, 2.85 vs. $2.03, \mathrm{p}<0.0001$ for implant removal, 2.7 vs. $1.96, \mathrm{p}<0.0001$ for elastic traction, 1.85 vs. $1.23, \mathrm{p}=0.01$ for implant movement, and 2.55 vs. $2.16, \mathrm{p}=0.02$ for gingiva/bone pain around the implant).

The sub-analysis of pain intensity according to different age groups showed that patients between 18-21 years were the most sensitive to pain (subgroup A, $n=18,36 \%$ ) (Table 3).

There were no statistically significant differences between subjects aged $<18$ years and $>21$ years in respect to pain perceived during any of the implant-related procedures; however, there were statistically significant differences between subjects $<18$ years and $18-21$ years, as well as subjects aged $18-21$ years and $>21$ years in almost all of these procedures (Table 4).

Another interesting observation was that pain intensity was significantly higher in the subgroup of patients who presented implant movement during the post-implantation period, especially regarding implant placement (PI 2.78 vs. $2.25, \mathrm{p}=0.03$ ), implant removal (PI 2.71 vs. $2.22, \mathrm{p}$ $=0.01$ ), and elastic traction anchorage (PI 2.64 vs. 2.11, p = 0.006) (Figure 4). However, there were no statistically significant differences between the groups with and without implant movement regarding the intensity of the gingiva/ bone pain during follow-up (PI 2.42 vs. $2.27, \mathrm{p}=0.4$ ), in-

TABLE 4. Pain intensity during implant-related procedures, by age

\begin{tabular}{|c|c|c|c|c|c|c|c|c|c|}
\hline & \multicolumn{2}{|c|}{$\begin{array}{c}\text { Age }<18 \text { years } \\
n=14(28 \%) \\
A\end{array}$} & \multicolumn{2}{|c|}{$\begin{array}{c}\text { Age 18-21 years } \\
\qquad \begin{array}{c}n=18(36 \%) \\
B\end{array}\end{array}$} & \multicolumn{2}{|c|}{$\begin{array}{c}\text { Age }>21 \text { years } \\
n=18(36 \%) \\
C\end{array}$} & \multicolumn{3}{|c|}{ p value } \\
\hline & Mean \pm SD & $95 \% \mathrm{Cl}$ & Mean \pm SD & $95 \% \mathrm{Cl}$ & Mean \pm SD & $95 \% \mathrm{Cl}$ & A vs. $B$ & B vs. C & A vs. C \\
\hline Pain intensity during anesthesia & $1.6 \pm 0.5$ & $1.35-1.93$ & $1.72 \pm 0.46$ & $1.49-1.95$ & $1.38 \pm 0.5$ & $1.13-1.63$ & 0.6 & 0.04 & 0.1 \\
\hline Pain intensity during implant placement & $2.21 \pm 0.8$ & $1.75-2.42$ & $2.83 \pm 0.78$ & $2.44-3.22$ & $2.11 \pm 0.6$ & $1.7-2.4$ & 0.3 & 0.005 & 0.6 \\
\hline Pain intensity during implant removal & $2.14 \pm 0.53$ & $1.83-2.32$ & $2.66 \pm 0.68$ & $2.32-3.00$ & $2.22 \pm 0.6$ & $1.9-2.5$ & 0.02 & 0.005 & 0.7 \\
\hline Pain intensity during implant movement & $1.07 \pm 0.6$ & $0.7-1.4$ & $1.94 \pm 0.9$ & $1.44-2.44$ & $1.33 \pm 0.7$ & $0.95-1.71$ & 0.007 & 0.04 & 0.3 \\
\hline Pain intensity during elastic traction & $2.14 \pm 0.53$ & $1.83-2.45$ & $2.66 \pm 0.59$ & $2.37-2.96$ & $1.94 \pm 0.53$ & $1.67-2.21$ & 0.01 & 0.0005 & 0.3 \\
\hline Gingival/bone pain around the implant & $2.14 \pm 0.53$ & $1.83-2.45$ & $2.55 \pm 0.61$ & $2.24-286$ & $2.22 \pm 0.54$ & $1.95-2.49$ & 0.06 & 0.09 & 0.6 \\
\hline
\end{tabular}




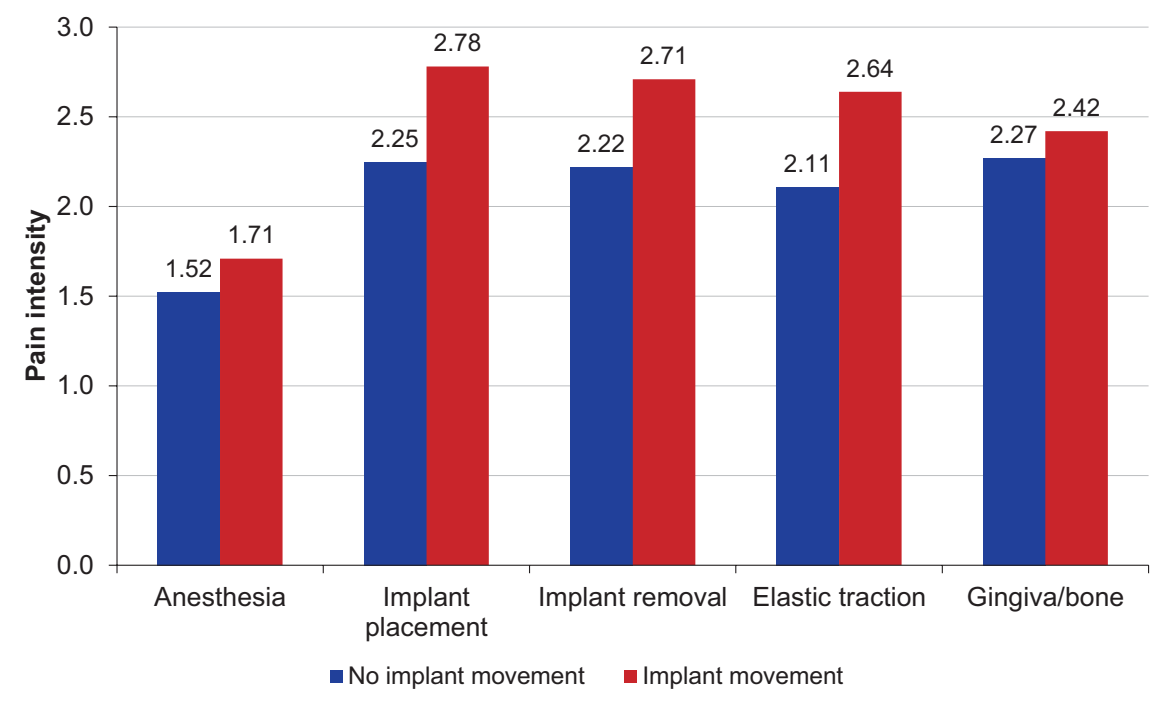

FIGURE 4. Pain intensity with vs. without implant movement

dicating that this type of pain has no correlation with the movement of the implant.

\section{DISCUSSIONS}

After the introduction of temporary skeletal anchorages, devices such as mini-implants modified with intraoral attachments have been used as an alternative to classic toothsupported anchorage. According to Cornelis et al., currently published studies in the orthodontic field tend to focus on mini-implants, which seem to be easier to place, probably because of their small size. ${ }^{14}$ However, mini-implants have been associated with a fairly high rate of failure and complications, including fracture during placement, loosening under loading, or impingement on roots either during placement or tooth movement. ${ }^{14}$ Despite the widespread use of these treatments, patients are apprehensive when they need to undergo mini-implant procedures, mainly because of the pain that accompanies the procedure. ${ }^{15}$

The mini-implant system was successfully used in this study as a skeletal anchor, and the patients supported well the pain and discomfort associated with the treatment. Pain and discomfort were mostly moderate while masticating sticky, fibrous, and firm foods. Mild pain was mostly reported during tooth brushing.

We used the visual analogue scale to record pain intensity in our study. It was chosen due to its easy clinical applicability and great power of pain measurement. These scales have also been proven to be valid for children and adolescents. ${ }^{16,17}$ Analysis of the patients' acceptance factors regarding the use of mini-implants during orthodontic treatment revealed that infiltrative anesthesia is one of the procedures most frequently rejected by the patients. Recent studies suggested the placement of implants under topical anesthesia, this type of anesthesia presenting several benefits such as patient acceptance, and easy and comfortable placement. However, it has been reported that $62.5 \%$ of patients felt pain during orthodontic treatment under topical anesthesia, due to the incomplete level of achieved anesthesia..$^{15}$ As a result, until further development of more efficient topical anesthetics, the infiltration method has remained the most commonly used type of anesthesia.

The results of our study indicate low levels of pain perception related to the anesthetic procedure, which seems to be easily tolerated by the patients.

Previous studies confirmed that orthodontic surgical procedures are well tolerated by patients. ${ }^{11,19,20}$ In a study by Cornelis et al., $82 \%$ of subjects stated that the surgical experience was better than expected, with little pain. ${ }^{14}$ However, Justens et al. reported that patients had complained of pain in $40-50 \%$ of cases, during or after surgery. However, this did not negatively affect the final general satisfaction with the treatment. ${ }^{18}$

The most frequent problems described in relation to surgical treatment were postsurgical swelling, lasting 5 days on average, and cheek irritation, which was experienced initially by more than a third of the patients and lessened over time.

Feldmann et al. reported that the individual variation in perceived pain intensity was overall large. ${ }^{6}$ The pain scores ranged from no pain at all to the worst imaginable pain. Median values for pain intensity and discomfort were comparatively moderate, but some patients described it as the 
worst imaginable. Moreover, the perception of pain intensity is also subjective and influenced by many other factors such as anxiety levels and motivational attitude.

In our study, the factors that presented a superior association with pain were male gender and age between 18 and 21 years. These results confirm the hypothesis that there is higher susceptibility to pain in male subjects and, at the same time, in a certain age group. The age group of 18-21 years is usually associated with a slightly higher degree of emotional disturbances, and this could explain the higher level of pain perception at this age. The situation tends to improve in subjects over 21 years, with pain perception values close to that obtained by those below 18 years.

The association of pain intensity with male gender and with the age group of 18-21 years during or after orthodontic treatment has not been described before. According to the authors' knowledge, this is the first study demonstrating a very strong association between these factors and pain intensity in patients undergoing orthodontic treatment.

In general, any delay in orthodontic treatment would result in emergencies. However, emergencies, pain and disability experienced by patients, especially in the event of a pandemic, were not very high as normally reported by the patients. This should help decision-makers evaluate risks versus benefits when it comes to resumption of clinical operations in case of a future disease outbreak..$^{21,22}$

\section{CONCLUSIONS}

In this study, pain perception during orthodontic treatment was significantly higher in males than in females, and in the age group of 18 to 21 years. The most painful procedure during orthodontic treatment was the initial moment when the implant was placed, followed by the moment of implant removal, while gingiva/bone pain around the implant and elastic traction anchorage was associated with lower degrees of pain.

\section{CONFLICT OF INTEREST}

Nothing to declare.

\section{REFERENCES}

1. Koh D. COVID-19 lockdowns throughout the world. Occup Med (Lond). 2020;kqaa 073.

2. Wilder-Smith A, Freedman DO. Isolation, quarantine, social distancing and community containment: pivotal role for old-style public health measures in the novel coronavirus (2019-nCoV) outbreak. J Travel Med. 2020;27:taaa020.

3. Meng L, Hua F, Bian, Z. Coronavirus Disease 2019 (COVID-19): emerging and future challenges for dental and oral medicine. J Dent Res. 2020;99:481e7.

4. Caprioglio A, Pizzetti G, Zecca PA, Fastuca R, Maino G, Nanda R. Management of orthodontic emergencies during 2019-NCOV. Prog Orthod. 2020;21:10

5. Dowsing P, Murray A, Sandler J. Emergencies in orthodontics part 1 management of general orthodontic problems as well as common problems with fixed appliances. Dent Update. 2015;42:131e40.

6. Feldmann I, List T, Bondemark L. Orthodontic anchoring techniques and its influence on pain, discomfort, and jaw function-a randomized controlled trial. Eur J Orthod. 2012;34:102-108.

7. Kvam E, Gjerdet NR, Bondevik O. Traumatic ulcers and pain during orthodontic treatment. Community Dent Oral Epidemiol. 1987;15:104-107.

8. Scheurer PA, Firestone AR, Burgin WB. Perception of pain as a result of orthodontic treatment with fixed appliances. Eur J Orthod. 1996;18:349357.

9. Marković E, Fercec J, Šćepan I, et al. The correlation between pain perception among patients with six different orthodontic archwires and the degree of dental crowding. Srp Arh Celok Lek. 2015;143:134-140.

10. Ngan P, Kess B, Wilson S. Perception of discomfort by patients undergoing orthodontic treatment. Am J Orthod Dentofacial Orthop. 1989;96:47-53.

11. Wilson S, Ngan, P, Kess B. Time course of the discomfort in young patients undergoing orthodontic treatment. Pediatr Dent. 1989;11:107-110.

12. Jones $\mathrm{M}$, Chan $\mathrm{C}$. The pain and discomfort experienced during orthodontic treatment: a randomized controlled clinical trial of two initial aligning arch wires. Am J Orthod Dentofacial Orthop. 1992;102:373-381.

13. Miller KB, McGorray SP, Womack R, et al. A comparison of treatment impacts between Invisalign aligner and fixed appliance therapy during the first week of treatment. Am J Orthod Dentofacial Orthop. 2007;131:302. e1-9.

14. Cornelis MA, Scheffler NR, Nyssen-Behets C, De Clerck HJ, Tulloch JF. Patients' and orthodontists' perceptions of miniplates used for temporary skeletal anchorage: a prospective study. Am J Orthod Dentofacial Orthop. 2008;133:18-24

15. Valieri MM, de Freitas KM, Valarelli FP, Cançado RH. Comparison of topica and infiltration anesthesia for orthodontic mini-implant placement. Dental Press J Orthod. 2014;19:76-83.

16. Abu-Saad H. Assessing children's responses to pain. Pain.1984:19:163-171.

17. McQuary H, Moore A. An evidence-based resource for pain relief. Oxford University Press, Oxford, United Kingdom. 1998; p. 272.

18. Justens E, De Bruyn $H$. Clinical outcome of mini-screws used as orthodontic anchorage. Clin Implant Dent Relat Res. 2008;10:174-180.

19. Sandler J, Benson PE, Doyle P, et al. Palatal implants are a good alternative to headgear: a randomized trial. Am J Orthod Dentofacial Orthop. 2008;133:51-57

20. Baxmann M, McDonald F, Bourauel C, Jäger A. Expectations, acceptance, and preferences regarding microimplant treatment in orthodontic patients: A randomized controlled trial. Am J Orthod Dentofacial Orthop. 2010;138:250.e1-250.e10.

21. Turkistani KA. Impact of delayed orthodontic care during COVID-19 pandemic: Emergency, disability, and pain. J World Fed Orthod. 2020;9:106e111

22. Vaida L, Muțiu G, Țara IG, Bodog F. An Algorithm of Ethical Approach to the Orthodontic Patients. Iran J Public Health. 2015;44:1296-1298. 


\section{Appendix 1}

\section{QUESTIONNAIRE}

\section{Pain sensation evaluation during orthodontic mini-implant placement}

1. On a scale from 1 to 4 , where 1 represents very mild pain and 4 represents severe pain, how would you describe the pain you felt during the infiltrative anesthesia before the insertion of a mini-implant?
1 Very mild
2 Mild
3 Moderate
4 Severe

2. On a scale from 1 to 4 , where 1 represents very mild pain and 4 represents severe pain, how would you describe the pain you felt during the implant placement?
1 Very mild
2 Mild
3 Moderate
4 Severe

3. During the elastic traction on mini-implants, did you feel pain at any moment?

Yes

No

4. If you answered affirmative at the above question, on a scale from 1 to 4 , where 1 represents very mild pain and 4 represents severe pain, how would you describe the pain you felt during the elastic traction?

1 Very mild 2 Mild 3 Moderate 4 Severe

5. During the orthodontic treatment with anchorage on mini-implants, did you feel any pain in the gingiva/ bone around the implant?

Yes No

6. If you answered affirmative at the above question, on a scale from 1 to 4 , where 1 represents very mild pain and 4 represents severe pain, how would you describe the intensity of the gingival/bone pain around the implant?
1 Very mild
2 Mild
3 Moderate
4 Severe

7. On a scale from 1 to 4 , where 1 represents very mild pain and 4 represents severe pain, how would you describe the pain you felt during implant movement in the postoperative period?
1 Very mild
2 Mild
3 Moderate
4 Severe

8. On a scale from 1 to 4 , where 1 represents very mild pain and 4 represents severe pain, how would you describe the pain you felt during the removal of the mini-implant?
1 Very mild
2 Mild
3 Moderate
4 Severe 